\title{
GLYPHOSATE AFFECTS SOYBEAN ROOT EXUDATION AND RHIZOSPHERE MICROORGANISMS
}

\author{
ROBERT J. KREMER ${ }^{\mathrm{a},{ }^{*}, \text { NATHAN E. MEANS }}{ }^{\mathrm{b}}$, and SUJUNG KIM ${ }^{\mathrm{b}}$ \\ ${ }^{a}$ United States Department of Agriculture, Agricultural Research Service, Cropping Systems \& \\ Water Quality Research Unit, Columbia, MO 65211, USA; \\ ${ }^{\mathrm{b}}$ Department of Soil, Environmental \& Atmospheric Sciences, University of Missouri, \\ Columbia, MO 65211, USA \\ *Corresponding author. Phone: 573-882-6408. Fax: 573-884-5070. Email: \\ KremerR@missouri.edu
}

\footnotetext{
- Mention of trade names or commercial products in this article is solely for the purpose of providing specific information and does not imply recommendation or endorsement by the U.S. Department of Agriculture or the University of Missouri.
} 
Glyphosate is a nonselective, broad-spectrum herbicide that kills plants by inhibiting the enzyme 5-enolpyruvylshikimic acid-3-phosphate synthase (EPSPS), which is necessary for synthesis of aromatic amino acids. A secondary mode of action involves infection of roots by soilborne microorganisms due to decreased production of plant protection compounds known as phytoalexins. Varieties of several crops, including glyphosate-resistant (GR) or Roundup Ready ${ }^{\circledR}$ soybean, are genetically modified to resist the herbicidal effects of glyphosate and provide farmers with an effective weed management tool. After glyphosate is applied to GR soybean, glyphosate that is not bound to glyphosate-resistant EPSPS is translocated throughout the plant and accumulates primarily in meristematic tissues. We previously reported that fungal colonization of GR soybean roots increased significantly after application of glyphosate but not after conventional postemergence herbicides. Because glyphosate may be released into soil from GR roots, we characterized the response of rhizosphere fungi and bacteria to root exudates from GR and non-GR cultivars treated with and without glyphosate at field application rates. Using an immunoassay technique, the flux of glyphosate detected in exudates of hydroponically-grown GR soybean was $>1000 \mathrm{ng}$ plant $^{-1}$ over the 16-d post-glyphosate application period. Glyphosate also increased carbohydrate and amino acid contents in root exudates in both soybean cultivars. However, GR soybean released higher carbohydrate and amino acid contents in root exudates than non-GR soybean without glyphosate treatment. In vitro bioassays showed that glyphosate in the exudates stimulated growth of selected rhizosphere fungi, possibly by providing a selective $\mathrm{C}$ and $\mathrm{N}$ source combined with the high levels of soluble carbohydrates and amino acids associated with glyphosate treatment of the soybean plants. Increased fungal populations that develop under glyphosate treatment of GR soybean may adversely affect plant growth and biological processes in the soil and rhizosphere.

Key words: Glyphosate, Immunosorbent assay, Fusarium, Rhizosphere microorganisms; Soybean root exudates

\section{INTRODUCTION}

Glyphosate is a non-selective, broad-spectrum herbicide that is widely used for weed management but also injures or kills crops when in direct contact with foliage. Glyphosate competitively inhibits 5-enolpyruvylshikimate-3-phosphate synthase (EPSPS), an enzyme in the shikimate pathway, which leads to synthesis of aromatic amino acids and other ring-containing metabolites [1]. Glyphosate is systemic within the plant, generally undergoes little or no metabolism in most plants, is readily translocated into metabolic sinks including plant roots [1] and is eventually released into the rhizosphere [2], likely via a diffusion process along with sugars, amino acids, and other low molecular weight compounds [3]. Glyphosate applied at label rates caused accumulation of $\leq 0.3 \mathrm{mM}$ glyphosate in root tissues of susceptible plants [4]. Glyphosate-resistant (GR) soybeans (Glycine max) are genetically modified to produce glyphosate-insensitive EPSPS [5]. GR soybean cultivars provide an additional weed management tool that reduces preemergence herbicide use and tillage [6]. Soybean production area planted to GR soybean since its introduction in 1996 expanded to $>85 \%$ in 2003 [7]. In GR soybean, a small amount of glyphosate is bound to EPSPS and, because very little is degraded within the plant [8], most of the remaining herbicide is translocated to active metabolic sinks including seeds [9], nodules [10], and roots [11].

The fate of glyphosate released with substances from plant roots is not well described. In previous reports, glyphosate applied to susceptible plants resulted in heavy colonization of roots by soilborne fungi, primarily Fusarium and Phytophthora $[12,13]$. Factors for the increased 
fungal colonization were not clearly known, however, root infection may be due to shutdown of production of antifungal compounds known as phytoalexins, which are synthesized by the plant via the shikimate pathway [14]. Recent reports suggest that roots of GR soybean cultivars treated with glyphosate may be colonized at a considerably higher density by Fusarium spp. compared to either GR soybean or non-GR soybean without glyphosate [15]. Gressel [16] suggests that the transgenic EPSPS in GR soybean is considerably less efficient than the wild-type enzyme and produces insufficient amounts of phytoalexins to prevent fungal infection. However, if glyphosate is readily released into the rhizosphere by GR soybean, the herbicide could also influence the composition of the microbial community and perhaps enhance certain microorganisms that may be pathogenic to GR soybean and cause a buildup of detrimental species that may affect subsequent crops. Limited evidence provided in recent reports suggests that glyphosate influences soil and rhizosphere microorganisms. Microbial activity appears to be enhanced by glyphosate that encountered the surface $2 \mathrm{~mm}$ of soil [17]. Glyphosate added to sandy-clay previously treated with glyphosate exhibited a selective effect for specific fungal species that were able use the herbicide as a nutrient source [18]. Release of carbohydrates and amino acids from roots by susceptible plants was increased when treated with glyphosate [2]. Increased concentrations of carbohydrates and amino acids resulting from herbicide treatment can profoundly alter the composition and activity of the microbial community in the rhizosphere $[3,19]$.

Therefore, glyphosate released from roots of soybean that is genetically modified for glyphosate resistance may affect microbial populations and/or activity in the rhizosphere. The objectives of this study were to demonstrate that glyphosate was released from roots of GR soybean; determine changes in concentrations of other major chemical constituents released by roots due to glyphosate treatment; and determine the effects of glyphosate in soybean root exudates on growth of selected rhizosphere microorganisms.

\section{EXPERIMENTAL}

\section{Soybean growth and glyphosate treatment}

Plants of glyphosate-resistant (GR; 'Pioneer 94B01') and conventional, glyphosate-susceptible (W82; 'Williams 82') soybean cultivars were grown hydroponically in sterile growth pouches (Mega International, Minneapolis, MN). The growth pouches consist of plastic bags (16 X18 cm) with germination paper wicks containing $50 \mathrm{ml}$ filter-sterilized nutrient solution [20]. This growth pouch system is based on [21], where it was used for collecting nitrogen-containing compounds exuded by soybean roots. The growth pouches were placed in a rack to maintain an upright position. Seeds of each soybean cultivar were surface sterilized by immersing in $1.25 \%$ sodium hypochlorite for $4 \mathrm{~min}$, rinsing in sterile water, immersing in $70 \%$ ethanol, rinsing five times in sterile water, and blotting on autoclaved paper towel. Surface-sterilized seeds of each cultivar were aseptically placed in the trough formed by the paper wick in each growth pouch that allowed seedling roots to grow through a perforated fold in the trough into the nutrient solution. Two seeds were placed per pouch, and five replicate pouches were prepared for each cultivar-herbicide treatment combination. Soybean plants were grown at $25 \pm 3^{\circ} \mathrm{C}$ under a $12 \mathrm{~h}$ light-dark photoperiod. At $14 \mathrm{~d}$ of growth (one trifoliate leaf stage), glyphosate formulated as Roundup Ultra ${ }^{\circledR}\left(480 \mathrm{~g}\right.$ ae L $\mathrm{L}^{-1}$; Monsanto, St. Louis, MO) was applied to soybean foliage at a rate corresponding to $0.84 \mathrm{~kg}$ ae $\mathrm{ha}^{-1}$ using a hand-held sprayer. The top, open ends of the growth pouches were covered with foil to prevent entry of glyphosate into the nutrient solution. Control 
treatments with no glyphosate were included for each soybean cultivar. At 2, 4, 8, 12, and $16 \mathrm{~d}$ after glyphosate application, nutrient solution $(50 \mathrm{ml})$ in each pouch was removed, dispensed into tubes, and stored at $-20^{\circ} \mathrm{C}$ until analyses. After sampling, each pouch was replenished with $50 \mathrm{ml}$ of fresh nutrient solution. Nutrient solution $\mathrm{pH}$ was maintained at 6.0 throughout the study. The growth pouch studies were conducted two times.

\section{Analyses of root exudates}

Nutrient solution collected from growth pouches during the sampling period was analyzed for the presence of glyphosate, soluble carbohydrates, and ninhydrin-reactive nitrogenous compounds, including amino acids that were released as root exudates. Glyphosate was quantified in duplicate 50- $\mu$ l aliquots of each nutrient solution sample by an enzyme-linked immunosorbent assay (Abraxis LLC, Warminster, PA) using the protocol provided by the manufacturer. The detection limit of the assay was $0.1 \mathrm{ng} \mathrm{g}^{-1}$ glyphosate. Glyphosate concentration in root exudates was expressed on a per plant basis.

Soluble carbohydrate content was determined by reacting the nutrient solution with the anthrone reagent and analyzing for absorbance at $625 \mathrm{~nm}$ against glucose standards [22]. Total soluble carbohydrates were expressed as glucose equivalents per plant.

Quantitation of amino acid content was based on the ninhydrin nitrogen reaction and essentially followed the procedure of Joergensen [23] except that a commercially available prepared ninhydrin reagent (\#N7285, Sigma, St. Louis, MO) was used. Ninhydrin-reactive nitrogen contents were expressed as amino acid concentration per plant.

\section{Microbiological assays}

Fungal cultures previously isolated from roots of field-grown soybeans in plot trials in Missouri [15] were maintained on potato dextrose agar (PDA) and stored at $4^{\circ} \mathrm{C}$ until use. The fungi used in this study were tentatively identified as Fusarium spp. based on descriptions of cultural and microscopic morphologies [24]. Fungal inocula for bioassays were prepared from 5-d old cultures of fungi on PDA from which 5-mm plugs of agar plus mycelia were removed from the actively growing edge of a fungal colony with a sterilized cork borer. Bacteria isolated from rhizospheres of field-grown soybeans (Kim, unpublished manuscript), were maintained in modified King's B medium [25] and stored at $4^{\circ} \mathrm{C}$ until use. Bacterial cultures were identified as Pseudomonas spp. using gas chromatographic analysis of methyl esters of fatty acids extracted from bacterial cells [26]. Bacterial inocula were prepared by suspending growth from 48-h cultures in phosphate buffered saline (PBS; $10 \mathrm{mM} \mathrm{K}_{2} \mathrm{PO}_{4}-\mathrm{KH}_{2} \mathrm{PO}_{4}, 140 \mathrm{mM} \mathrm{NaCl} ; \mathrm{pH} 7.2$ ) and adjusting to a concentration of $10^{8}$ colony-forming units (cfu) $\mathrm{ml}^{-1}$.

Growth of microorganisms in nutrient solution containing root exudates collected from the hydroponically-grown soybeans was determined by dispensing 750-ul aliquots into each well of 24-well microtiter plates (Nunc InnterMed, Roskilde, Denmark). For fungi, one agar plug was placed per well; four replicate wells were inoculated for each root-exudate fungus combination. Fungal bioassays were incubated in the dark at $27^{\circ} \mathrm{C}$. After $28 \mathrm{~d}$, mycelial mats developed in each well were removed with a spatula, placed on pre-weighed filter papers, and air-dried for $6 \mathrm{~h}$ at room temperature under a laminar flow hood prior to weighing. For bacteria, 50 ul of inocula were dispensed into each well and plates were incubated in the dark at $27^{\circ} \mathrm{C}$ for $10 \mathrm{~d}$. After incubation, numbers of bacteria developing in the root exudates were enumerated by serial dilution in sterile PBS and plating on King's B agar medium. Plates were incubated at $27^{\circ} \mathrm{C}$ for 3

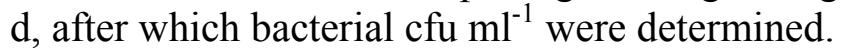


The growth response to glyphosate of the fungal and bacterial cultures was determined by amending basal salts medium $\left(3 \mathrm{~g} \mathrm{NaNO}_{3}, 0.5 \mathrm{~g} \mathrm{MgSO}_{4}, 1.0 \mathrm{~g} \mathrm{KCl}, 0.01 \mathrm{~g} \mathrm{FeSO}_{4}, 1.0 \mathrm{~g}\right.$ yeast extract per $1 \mathrm{~L}$ deionized water) with $0,1,500$, and $1000 \mathrm{uM}$ glyphosate. Inoculation, incubation conditions, and growth determinations for fungi and bacteria were as described above for growth in root exudates.

\section{Statistical analysis}

Data were subjected to analysis of variance and, when $F$ values were significant $(P<0.05)$, means were separated using Fisher's protected least significant difference (LSD) test to determine significance of treatment effects in chemical analyses of root exudates and in each microbial bioassay.

\section{RESULTS AND DISCUSSION}

Glyphosate was detected in root exudates of both GR and W82 soybean cultivars beginning at 2 $\mathrm{d}$ after glyphosate application with cumulative amounts steadily increasing through $12 \mathrm{~d}$ (Fig. 1). Concentrations ranged from 200 and $240 \mathrm{ng}$ per plant for GR and W82, respectively, at $2 \mathrm{~d}$ postapplication and accumulated to a total amount exuded of 1500 and $1100 \mathrm{ng}$ per plant for GR and W82 at $16 \mathrm{~d}$. Glyphosate translocation and release through rhizomes and roots of couch grass (Agropyron repens), a glyphosate-susceptible plant, followed a similar pattern of increasing concentrations in exudates over an 8-d sampling period [2]. Cumulative glyphosate concentration was significantly higher for the GR soybean at $16 \mathrm{~d}$ suggesting that exudation continued at a nearly constant rate in the live, intact root cells compared to the release of only trace amounts of glyphosate between 12 and $16 \mathrm{~d}$ after application by the glyphosate-susceptible W82 cultivar, in which exudation was apparently slowed by death of the plants. Others have reported that glyphosate is readily translocated into metabolic sinks including plant roots and nodules of glyphosate-susceptible and -resistant plants $[10,11])$ and is released from roots of susceptible plants [2, 27]; however, our results clearly demonstrate that intact glyphosate is also released from roots of actively-growing GR soybean. Glyphosate was not detected in root exudates of either GR or W82 plants that were not sprayed with glyphosate.

Soluble carbohydrate concentrations and rates of release as exudate components were similar for GR and W82 cultivars through $8 \mathrm{~d}$ after glyphosate application (Fig. 2). By $12 \mathrm{~d}$ postapplication, carbohydrate exudation began to level off for W82 but continued to increase for GR soybean. Carbohydrate exudation by W82 not treated with glyphosate was consistently lower than all other treatments throughout the sampling period. Interestingly, GR soybean without glyphosate treatment exuded carbohydrate at a consistently higher rate and, by day 8 , equaled the exudation rate of GR soybean that was treated with glyphosate.

Glyphosate applied to GR soybean increased amino acid concentrations in root exudates detectable at $4 \mathrm{~d}$ after application with the trend for increased exudation continuing for $16 \mathrm{~d}$ (Fig. 3). Amino acid exudation rates were essentially identical for glyphosate-treated W82 and the GR control treatment. The W82 control treatment showed significantly lower amino acid exudation from day 8 through day 16 . As observed for carbohydrate exudation, the GR cultivar receiving no glyphosate appeared to release inherently higher amounts of amino acids compared to the glyphosate-susceptible W82 cultivar without glyphosate. Simultaneous release of ninhydrinpositive compounds with glyphosate in root exudates from susceptible plants has previously been reported [2]. 
Our observations suggest that some mechanism(s) affecting carbohydrate and amino acid translocation and release through roots by GR soybean was affected during genetic modification for glyphosate resistance. Other unusual traits that were expressed by GR soybean have been reported and have been interpreted as inadvertent side-effects of the genetic transformation process or a flaw in the transgene itself [16].

We tested 12 different Fusarium strains for growth response in soybean root exudates. Growth of 5 strains increased in exudates from glyphosate-treated soybean. Representative Fusarium strains cultured in root exudates collected $16 \mathrm{~d}$ after glyphosate treatment yielded a range of growth responses (Table I). Fusarium strains 301 and 304 developed significantly higher biomass in root exudates of glyphosate-treated soybean with the highest biomass detected in exudates from the GR cultivar. Fusarium strain 206 growth in both W82 exudates was similar, however, growth was significantly higher in GR exudates regardless of glyphosate treatment.

Bacterial response differed from that of fungi. Of 3 representative strains, only Pseudomonas strain 39 growth increased in exudates from glyphosate-treated W82 soybean (Table I). Indeed, bacterial growth generally decreased in root exudates of glyphosate-treated plants. Previous research reported that glyphosate concentrations $<1 \mathrm{mM}$ inhibited growth of the symbiotic nitrogen fixing bacterium Bradyrhizobium japonicum [28] due to a combination of sensitivity of $B$. japonicum to glyphosate and the potential accumulation of cellular glyphosate that could interfere with nodulation and the nitrogen fixation process. Our pseudomonad isolates may also be sensitive to low glyphosate concentrations and therefore interfere with development of populations of beneficial rhizobacteria in the soybean rhizosphere [29].

Selected Fusarium strains cultured in known concentrations of glyphosate differed in growth response to glyphosate as a nutrient source (Fig. 4). Highest growth was achieved by strains 301 and 304, with strain 304 accumulating biomass in $1 \mu \mathrm{M}$ glyphosate that was about $50 \%$ of that in a complete nutrient medium (PDA). It is important to note that $1 \mu \mathrm{M}$ glyphosate approximates the flux in GR root exudates at 16 days post-treatment, on which microbial cultures were incubated (Table I). Other strains, i.e., Fusarium 110, grew poorly on glyphosate regardless of concentration. Pseudomonas strains did not show consistent growth on glyphosate as a nutrient source (data not shown).

This study demonstrated that label rates of glyphosate applied to a GR soybean resulted in exudation of glyphosate through roots, which coincided with exudation of high concentrations of soluble carbohydrates and amino acids, compared to plants receiving no glyphosate. Microbial bioassays demonstrated that selected fungi were stimulated to grow in root exudates containing both glyphosate and high levels of soluble carbohydrates and/or amino acids. Based on previous reports, the enhanced fungal growth observed in our study may be explained as follows.

Glyphosate in root exudates has a dual effect on selected fungi: it serves as a nutrient source, and it may also stimulate propagule germination and early growth [18]. Also, specific exudate molecules activate and stimulate germination of fungal propagules, which leads to initiation of plant infections by soilborne pathogens, especially when exudate component concentrations are higher than normal [30]. Propagules of nearly all common genera of soilborne pathogens respond to seed and root exudates, thought to primarily involve sugars and amino acids. Interestingly, bacteria may metabolize exudate components that stimulate fungal propagule germination thereby inhibiting fungal growth [30]. Thus, in our study, glyphosate may have blocked growth of bacteria and their ability to metabolize such chemical promoters that contribute to fungal proliferation. Fusarium spp. in particular may be more competitive for resources in the presence of glyphosate in the rhizosphere, which may also enhance antagonism toward other 
microorganisms and increase the proportion of the antagonistic Fusarium in the rhizosphere community [31]. Based on recent work of Griffiths et al. [32], steady increases in the release of substrates comprised of soluble carbohydrates and amino acids into simulated rhizospheres consistently increased the proportion of fungi in the rhizosphere community, to the point where fungi displaced nearly all bacteria residing in the rhizosphere. Therefore, the structure of the microbial community is not solely governed by composition of exudates but optimal growth of different microorganisms is related to quantity of available substrates. Thus, our study suggests that glyphosate released into the rhizosphere of GR soybean combined with release of high concentrations of carbohydrates and/or amino acids favored increased growth of selected Fusarium spp. This finding partly explains the high colonization of field-grown GR soybean roots by Fusarium [15].

\section{CONCLUSIONS}

The consequences of enhanced root colonization of GR crops include development of root disease by increased numbers of parasitic and opportunistic pathogens in the rhizosphere, competition with roots for nutrients, or selection and enrichment in soils of specific microorganisms that are either detrimental or beneficial for crop growth. Furthermore, detrimental fungi may build up in soil and become a potential problem for subsequent crops, especially GR crops, cultivated in the same field. A unique finding of this research is that glyphosate exhibits an indirect biological fate: translocation and release through roots, which influences soil microbial activity.

Results of these studies indicated that glyphosate released in root exudates stimulated growth of selected Fusarium spp. from the soybean rhizosphere. Results are preliminary and based on only 2 soybean cultivars and evaluation of a limited number of microbial cultures. More detailed studies on composition and diversity of rhizosphere microorganisms are necessary to confirm or describe further the effects of glyphosate released into rhizosphere on biodiversity and activities in soil. As pointed out by Reddy and Zablotowicz [10], hundreds of GR soybean cultivars are currently available and the physiological characteristics influencing exudation of glyphosate and other root substances may vary due to the genetics of the individual cultivar and depend on environmental conditions and soil variability in the field.

\section{Acknowledgements}

This research was partially supported through United States Department of Agriculture Special Grant Number 2003-06156 and a grant from Ag Spectrum Company, DeWitt, IA. The authors are grateful to Jenan Nichols, Sarah LaFrenz and Heidi Lewis for technical assistance.

\section{References}

(1) S.O. Duke, In: Herbicides: Chemistry, Degradation, and Mode of Action (P.C. Kearney and

D.D. Kaufman, eds., Marcel Dekker, New York, 1988) pp. 1-70.

(2) D. Coupland and J.C. Caseley, New Phytol., 83, 17-22 (1979). 
(3) E.A. Curl and B. Truelove, The Rhizosphere (Springer-Verlag, Berlin, 1986), 288pp.

(4) J.L. Honegger, J.M. Brooks, E.J. Anderson and C.A. Porter, In: Phloem Transport (J.

Cronshaw, ed., Liss, New York, 1986) pp. 609-618.

(5) K.N. Reddy, Weed Biol. Manage., 1, 193-202 (2001).

(6) R.M. Zablotowicz and K.N. Reddy, J. Environ. Qual., 33, 825-831 (2004).

(7) CropBiotech Net, Global Status of Commercialized Transgenic Crops: 2003 (2004).

[http://www.isaaa.org]

(8) M.C. Arregui, A. Lenardon, D. Sanchez, M.I. Maitre, R. Scotta and S. Enrique, Pest Manage.

Sci., 60, 163-166 (2003).

(9) S.O. Duke, A.M. Rimando, P.F. Pace, K.N. Reddy and R.J. Smeda, J. Agric. Food Chem., $51,340-344$ (2003).

(10) K.N. Reddy and R.M. Zablotowicz, Weed Sci., 51, 496-502 (2003).

(11) S.O. Duke, In: Herbicide-Resistant Crops: Agricultural, Environmental, Regulatory, and Technical Aspects (S.O. Duke, ed., CRC Press \& Lewis Publishers, Boca Raton, FL, 1996), pp. 1-10.

(12) G.S. Johal and J.E. Rahe, Phytopathology, 74, 950-955 (1984).

(13) C.A. Levesque and J.R. Rahe, Annu. Rev. Phytopathol., 30, 579-602 (1992).

(14) A. Sharon, Z. Amsellem and J. Gressel, Plant Physiol., 98, 654-659 (1992).

(15) R.J. Kremer, Phytopathology, 93, S104 (2003).

(16) J. Gressel, Molecular Biology of Weed Control (Taylor \& Francis, London, 2002), pp. 504.

(17) R.L. Haney, S.A. Senseman, F.M. Hons and D.A. Zuberer, Weed Sci., 48, 89-93 (2000).

(18) T. Krzysko-Lupicka and A. Orlik, Chemosphere, 34, 2601-2605 (1997). 
(19) M.J. Brimecombe, F.A. DeLeij and J.M. Lynch, In: The Rhizosphere: Biochemistry and Organic Substances at the Soil-Plant Interface (R. Pinton, Z. Varanini and P. Nannipieri, eds., Marcel Dekker, New York, 2001), pp. 95-140.

(20) P. Somasegaran and H.J. Hoben, Methods in Legume-Rhizobium Technology (NifTAL Project, Paia, HI, 1985), 367pp.

(21) R.J Maier and W.J. Brill, Science, 201, 448-450 (1978).

(22) R.H. Brink, P. Dubach and D.L. Lynch, Soil Sci., 89, 157-166 (1960)

(23) R.G. Joergensen, Soil Biol. Biochem., 28, 301-306 (1996).

(24) P.E. Nelson, T.A. Toussoun and.O Marasas, Fusarium Species: an Illustrated Manual for Identification (The Pennsylvania State University Press, University Park, PA, 1983), 193pp.

(25) D.C. Sands and A.D. Rovira, Appl. Microbiol. 20, 513-514 (1970).

(26) M. Sasser, In: Methods in Phytobacteriology (Z. Klement, K. Rudolph and D.C. Sands, eds., Akadamiai Kiado, Budapest, 1990) pp. 199-204.

(27) J.J.V. Rodrigues, A.D. Worsham and F.T. Corbin, Weed Sci., 30, 316-320 (1982).

(28) T.B. Moorman, J.M. Becerril, J. Lydon and S.O. Duke, J. Agric. Food Chem., 40, 289-293 (1992).

(29) A.J. Cattelan, P.G. Hartel and J.J. Fuhrmann, Soil Sci. Soc. Am. J., 62, 1549-1555 (1998).

(30) E.B. Nelson, In: The Rhizosphere and Plant Growth (D.L. Keister and P.B. Cregan, eds., Kluwer Academic Publishers, Dordrecht, The Netherlands, 1991), pp. 197-209.

(31) D.A. Wardle and D. Parkinson, Mycol. Res., 96, 180-186 (1992).

(32) B.S. Griffiths, K. Ritz, N. Ebblewhite and G. Dobson, Soil Biol. Biochem., 31, 145-153 (1999). 
TABLE I Growth of selected fungal and bacterial cultures in root exudates collected from hydroponically-grown soybean $16 \mathrm{~d}$ after glyphosate application. Fungal biomass was determined after $28 \mathrm{~d}$ incubation; bacterial populations were determined after $10 \mathrm{~d}$ incubation.

\begin{tabular}{|l|c|c|c|c|}
\hline & \multicolumn{2}{|c|}{ Williams 82 } & \multicolumn{2}{c|}{ Glyphosate-resistant } \\
\hline & No glyphosate & + Glyphosate & No glyphosate & + Glyphosate \\
\hline Fungal strains: & \multicolumn{4}{|c|}{ (mg fungal biomass) } \\
\hline Fusarium 110 & $10 \mathrm{a}^{*}$ & $10 \mathrm{a}$ & $10 \mathrm{a}$ & $8 \mathrm{a}$ \\
\hline Fusarium 206 & $31 \mathrm{~b}$ & $29 \mathrm{~b}$ & $36 \mathrm{a}$ & $35 \mathrm{a}$ \\
\hline Fusarium 301 & $14 \mathrm{~b}$ & $18 \mathrm{c}$ & $8 \mathrm{~d}$ & $27 \mathrm{a}$ \\
\hline Fusarium 304 & $20 \mathrm{c}$ & $24 \mathrm{~b}$ & $16 \mathrm{~d}$ & $28 \mathrm{a}$ \\
\hline & \multicolumn{5}{|c|}{$\mathrm{LSD}(0.05)=4$} \\
\hline & \multicolumn{5}{|c|}{$\left(\log _{10} \mathrm{cfu} \mathrm{m}^{-1}\right)$} \\
\hline & \multicolumn{5}{|c|}{$6.30 \mathrm{~b}$} & $5.78 \mathrm{~b}$ \\
\hline Bacterial strains: & $6.36 \mathrm{~b}$ & $7.36 \mathrm{a}$ & $6.54 \mathrm{~b}$ \\
\hline Pseudomonas 39 & $7.68 \mathrm{a}$ & $6.78 \mathrm{~b}$ & $7.54 \mathrm{a}$ & $6.32 \mathrm{a}$ \\
\hline Pseudomonas IRB & $7.16 \mathrm{a}$ & $6.76 \mathrm{a}$ & $6.30 \mathrm{a}$ \\
\hline P. fluorescens G211 & \multicolumn{5}{|c|}{ LSD $(0.05)=0.6$} \\
\hline
\end{tabular}

* Values within a row followed by the same letter are not significantly different. 
FIGURE 1 Cumulative glyphosate in root exudates of conventional (W82) and glyphosateresistant (GR) soybean collected from a hydroponic system periodically after glyphosate treatment.

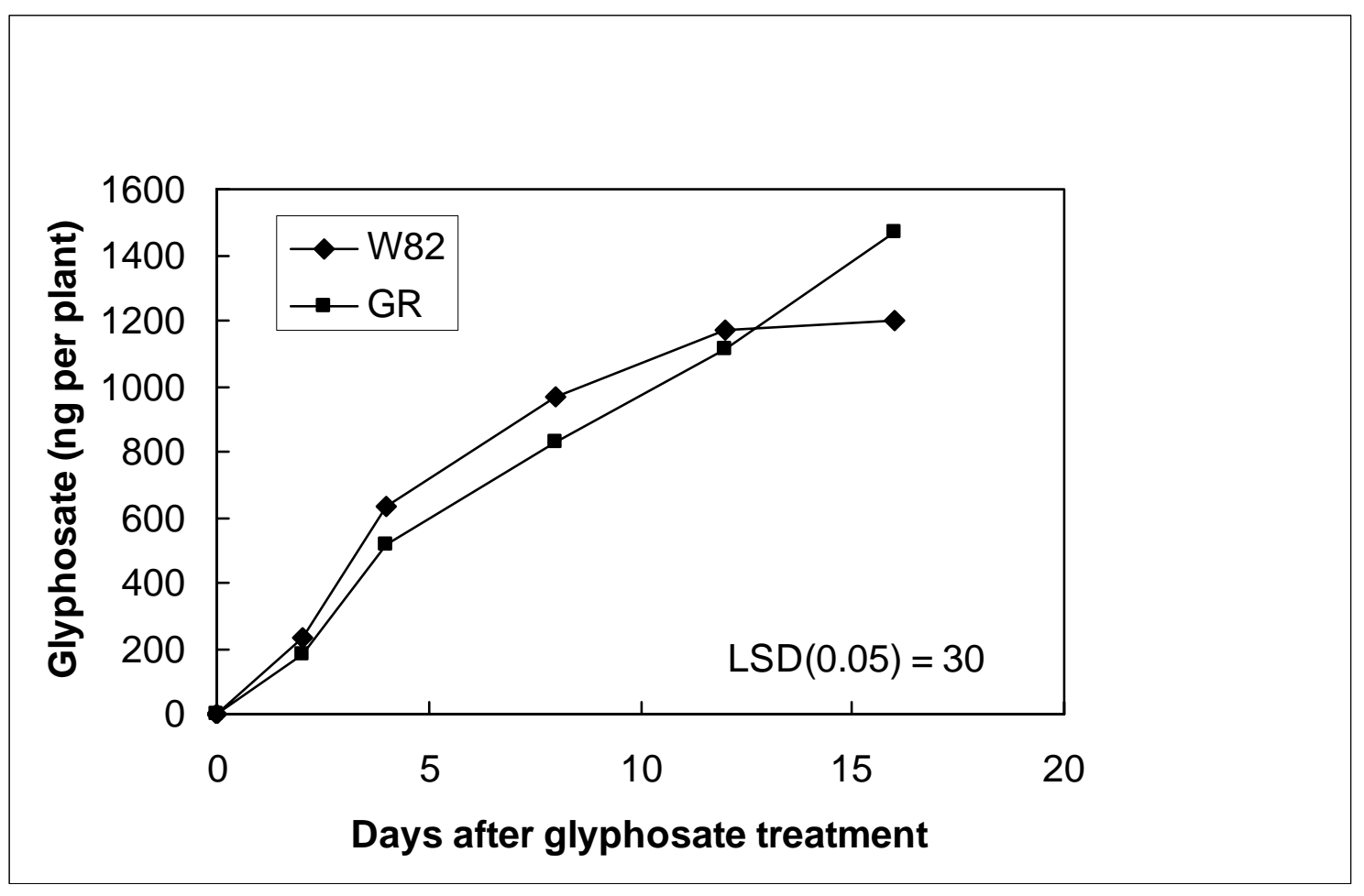


FIGURE 2 Cumulative carbohydrate contents in root exudates of conventional (W82) and glyphosate-resistant (GR) soybean collected from a hydroponic system periodically after glyphosate (Gly) treatment.

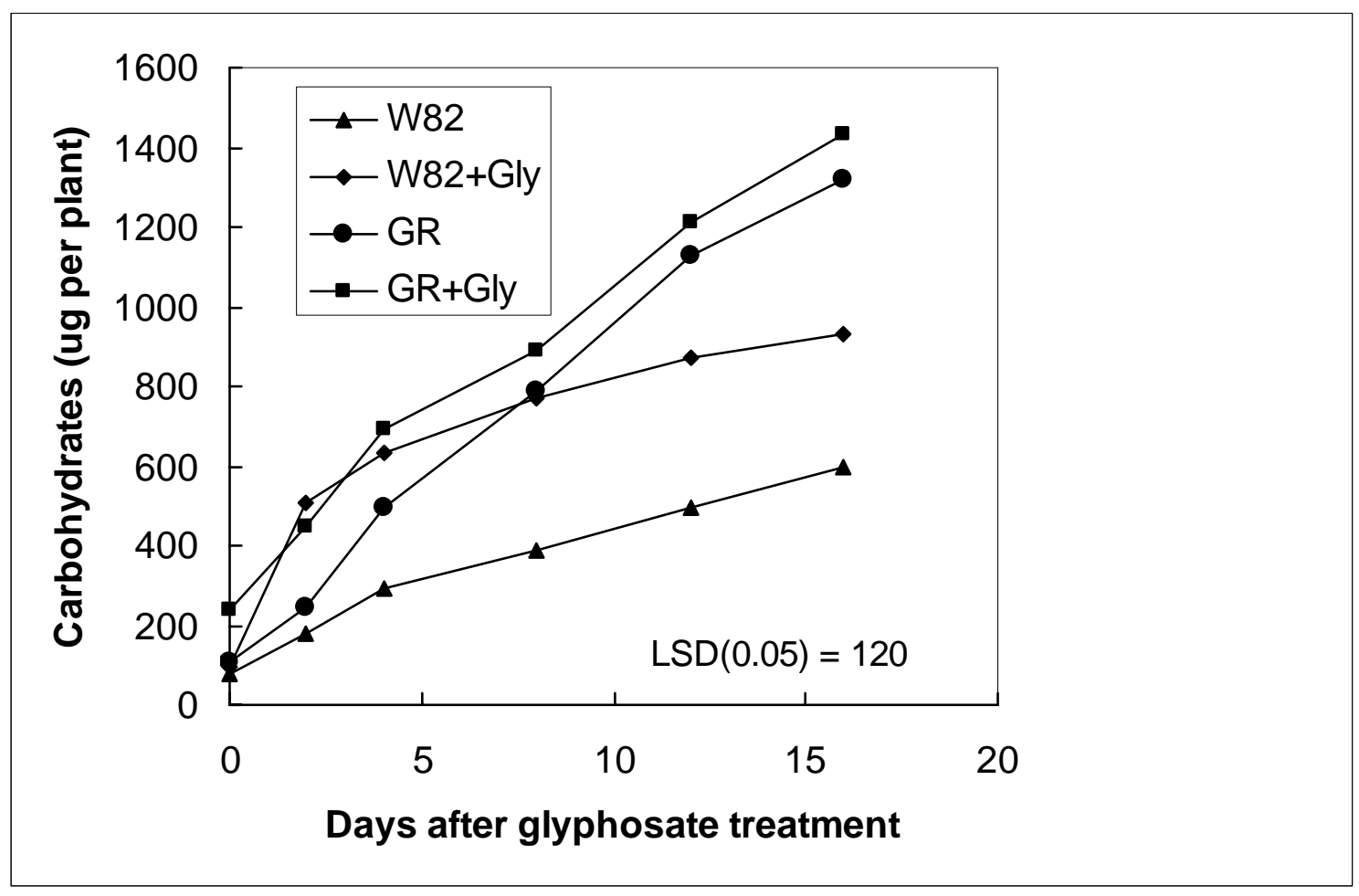


FIGURE 3 Cumulative amino acid contents in root exudates of conventional (W82) and glyphosate-resistant (GR) soybean collected from a hydroponic system periodically after glyphosate (Gly) treatment.

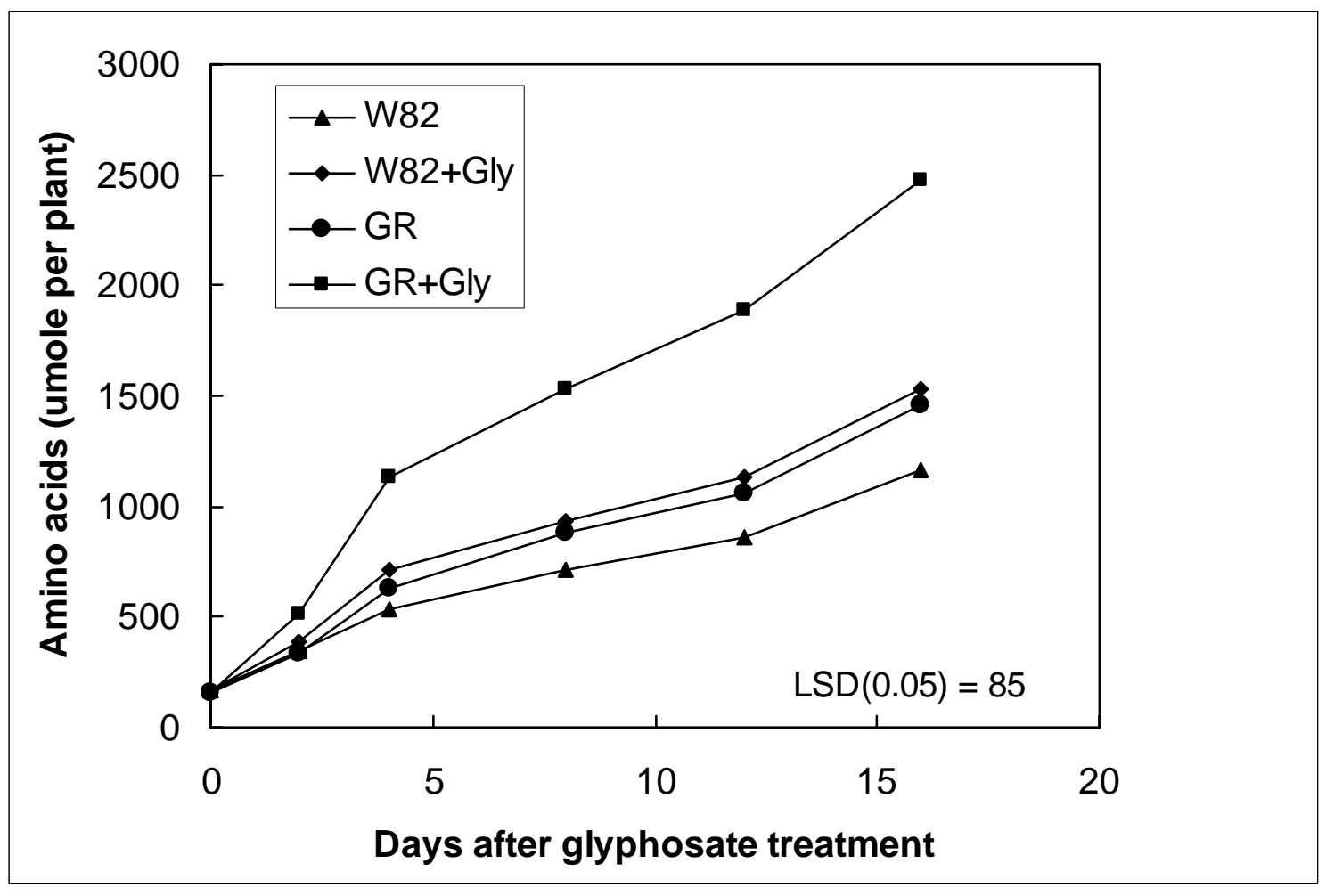


Figure 4. Growth response of selected Fusarium cultures to various concentrations of glyphosate (Gly) after $28 \mathrm{~d}$ incubation. PDA = potato dextrose agar, the control treatment.

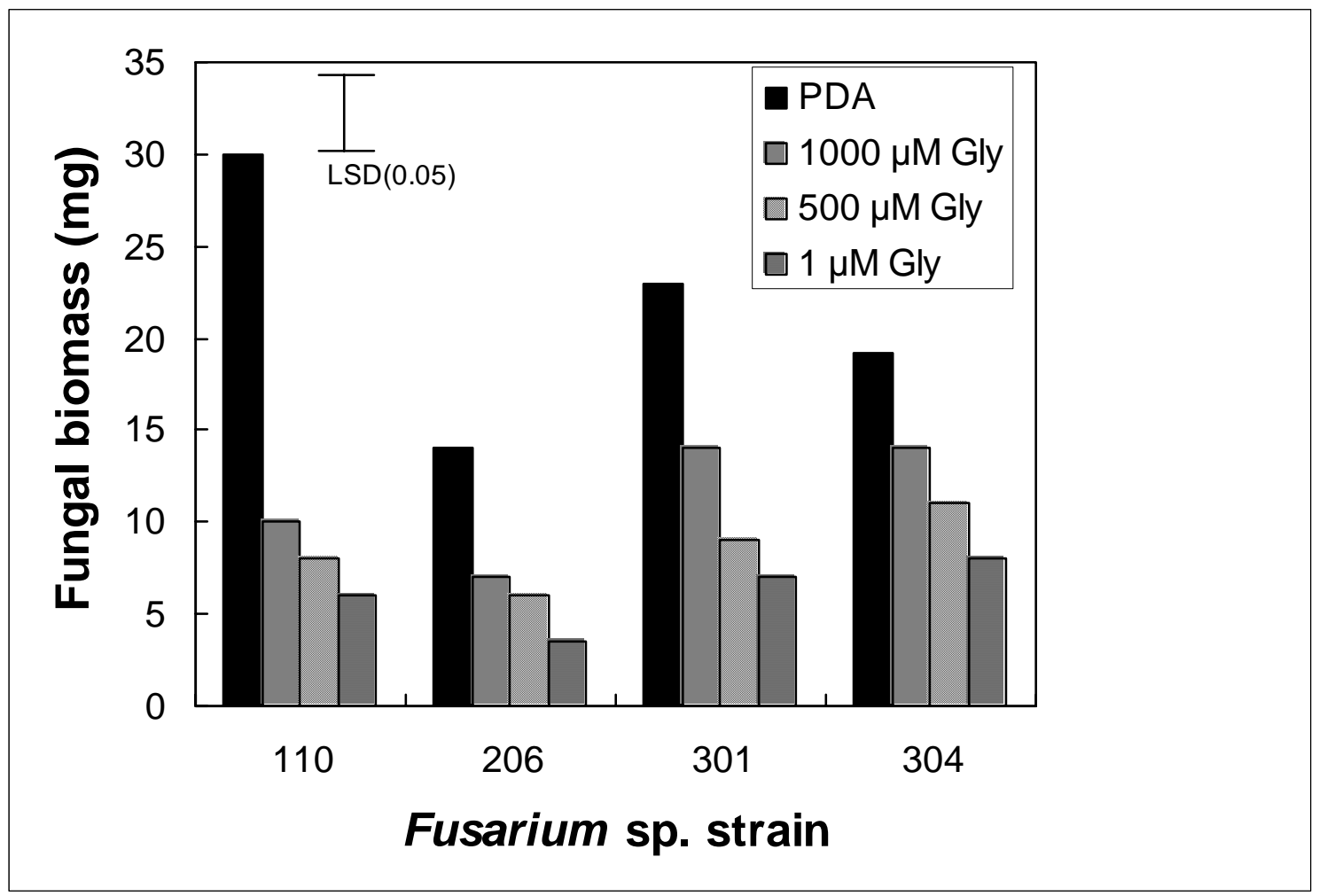

